Article

\title{
Exploring the Interactions of Factory Workers in China: A Model Development Using the Grounded Theory Approach
}

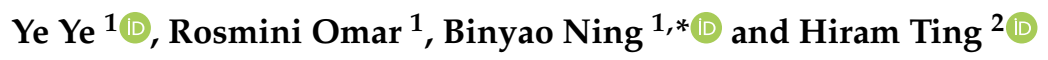 \\ 1 Azman Hashim International Business School, Universiti Teknologi Malaysia, \\ Kuala Lumpur 54100, Malaysia; yipyip2022@gmail.com (Y.Y.); rosmini@ibs.utm.my (R.O.) \\ 2 Faculty of Hospitality and Tourism Management, UCSI University, Sarawak 93450, Malaysia; \\ hiramparousia@gmail.com \\ * Correspondence: janetning1107@163.com
}

Received: 16 July 2020; Accepted: 19 August 2020; Published: 20 August 2020

\begin{abstract}
This study uses the grounded theory approach to explore factory workers to factory worker interaction (FWI) in the context of Chinese factories and proposes a model of FWI in the workplace. Human interaction in the workplace is indispensable in most sectors. Compared with large-scale factories, China's small and medium-sized enterprise (SME) factories lack capital resources and technological advancement, and sustainably managing factory workers is essential for the development of Chinese SME factories. However, previous studies have ignored FWI in Chinese factories. The model developed in this study considers the types, driving factors, and influential outcomes of FWI. The main factors affecting FWI are the individual characteristics of the workplace and external environmental factors and, among types of FWI, information sharing is the most dominant and prevailing. The managers' management style and the emotional state of factory workers are playing moderating roles in FWI. Results show that factory managers can take advantage of the positive impacts of FWI to improve the efficiency of factory workers and avoid its negative effects to achieve sustainable development of the factory. Theoretical and managerial implications are provided.
\end{abstract}

Keywords: factory worker to factory worker interaction; small and medium-size enterprise factories; human resource management; workplace; grounded theory; China

\section{Introduction}

Most Chinese factories adopt a military-style Taylorist management system [1], and believe that this style of human resource management (HRM) can effectively promote efficiency in their workers. Specifically, such factories' workers cannot walk around away from their appointed workstation and cannot talk with each other during working hours [1,2]. Factory workers' behavior in the workplace is controlled as closely as possible, and workers are treated as part of the production machinery. This style of management is particularly exemplified by the Foxconn manufacturing firm, which employs more than a million factory workers in China. It is difficult to deny the developmental achievements of China's factories in the past 20 years, but the HRM model used by Chinese factories remains controversial. Chinese factories have, for many decades, been described as "sweatshops" [3]; there have been concerns at rates at which employees have committed suicide [4], and the staff turnover rate is exceptionally high [5], but all the drawbacks are covered by the halo of the "world factory". Workplace interaction is essential in most industries [6], and especially in those that require collaboration between employees. Workplace interaction has proved to improve work efficiency and 
workers' sense of belonging effectively, but such benefits are ignored by the military-style Taylorist management system. Small and medium-sized enterprises (SMEs) usually seek to replicate the HRM of large enterprises, but have a predominance of informality in their workplace practices $[7,8]$. China's SME factories are not as well-equipped as large-scale factories in terms of capital, resources, and industrial chain. One potential area of the advantage of SMEs is their HRM, and the question of whether SMEs should adopt a strict military-style Taylorist management system or a relatively loose management model to gain sustainability, which is of interest to both academics and human resource managers of SME factories.

Interpersonal interaction theory emphasizes that the relationship between individuals is affected by their interactions [9]. Interpersonal interaction can be all-around. It is a different form of interaction between individuals and can bring about various interaction effects [10,11]. SMEs in China, however, are typically private companies and can generally be characterized as embracing "dictatorship" in their management style [12]. Research focusing on China's SME factories is limited to the relationship between superiors and subordinates, while factory worker to factory worker interaction (FWI) has been yet to take critical attention and be studied in depth.

As is recognized in the interpersonal interaction model, personality traits and working environments affect an individual to individual interactions [13]. Different working environments lead to differences in the interactions between individuals. Nonetheless, the individual interaction factors which have the most significant effect are personality traits and background [14,15]. Most factory workers in China come from rural areas. They have generally had a deprived childhood that has caused them to lack a good educational background [16], and this has typically caused their personality and behavior to differ significantly from people who grow up in cities. Moreover, factory work is not considered a desirable occupation in China [17], and the working environment is not as comfortable as that of civil servants, teachers, or employees in other kinds of companies. Factory work does not require specialized skills or a strong educational background. Jobs of this kind, that almost anyone is capable of performing, usually require more than $12 \mathrm{~h}$ of work per day, and the salary only reaches average levels [18]. Due to the particular nature of Chinese factory worker groups and the factory working environment, applying a previously developed study framework in the unmodified form to the analysis of FWI could lead to erroneous results.

Besides, Chinese SMEs pay more attention to performance management than larger firms [7]. As HRM practices can improve corporate competitiveness and organizational performance, they have become the focus of HRM research for SMEs. Nonetheless, unlike Western and Oriental developed countries, China's SMEs pay different attention to human resources management (HRM). Studies on HRM in Chinese SMEs and some developing countries focus primarily on effective employee recruitment and selection, high-level training, and high-performance work practices $[12,19,20]$, whereas Western societies and Eastern developed countries give greater consideration to achieving superior performance by improving employees' treatment and job attitudes [21,22]. In today's highly industrialized era, Chinese manufacturing managers are primarily concerned with the organizational performance gains brought about by upgrading machinery and technology, and ignore the importance of factory worker interaction. In studies on the sustainable development and competitive advantage of SME manufacturing enterprises, researchers tend to focus on the utilization rates of new machinery and equipment [23], the innovative ability of skilled workers [24], green development [25], and the quality and quantity of outputs [26]. Few studies analyze the role of factory workers based on HRM. However, in the current manufacturing industry, production machines remain unable to replace human labor completely. Factory workers need to engage in work-related interactions as part of their cooperative efforts to maintain the operation of the factory, but also require considerable non-work-related interactions to maintain morale and improve work efficiency [27]. China's SME factories have an average life span of only 3.7 years [28] and are typically focused on pursuing short-term interests. Purchasing a new production machine can bring immediate benefits. In contrast, worker interaction has not been effectively utilized to benefit productivity in large factories, nor has it been proven that 
it can effectively improve organizational performance and sustainability in SME factories. Hence at present, adoption of new HRM practices is unrealistic for SME factories [7]. FWI is similarly neglected in the existing HRM practices of SME factories.

Interpersonal interactions are highly dependent on specific situations, and for this reason, existing interpersonal interaction frameworks are insufficient to understand FWI in the SME workplace. The present study, therefore, aims to propose and develop a model to articulate the content, classification, driving factors, and influencing mechanisms of FWI in the context of SME manufacturing operations. This study enriches understanding of FWI from both theoretical and managerial aspects by extending knowledge pertaining to the impact of Chinese FWI on factory workers themselves and on factory productivity and outputs as well as the HRM of SME factories. A model is constructed based on the grounded theory methodology and the significance of the interaction between factory workers in the workplace is analyzed.

The remainder of this paper proceeds as follows. First, related studies have been reviewed that address the interaction of employees in the workplace, and specifically, the interaction of factory workers in SME factories in China. Then, the grounded theory approach which we adopt for this study is summarized. The next section elucidates the findings derived based on the theoretical categories identified during the theory-based process, and these findings are combined to construct our full model. Finally, we discuss the specific managerial and theoretical implications.

\section{Literature Review}

\subsection{Employee to Employee Interaction}

Interpersonal interaction theory is used to explain the behavior of individuals through the exchange of information [29], and is a field of social psychology research that emphasizes the role of interaction. In most workplaces, interaction with others is inevitable, and so working can be considered a social activity. Employee-to-employee interaction (EEI) is a terminology taken from the human resources literature and it refers to the relationship between employees in the workplace [30], and is the branch of interpersonal interaction most widely studied [31].

EEI is considered to have two main types: formal and informal interaction [32]. Formal interaction refers to interactions in professional roles (i.e., interactions that relate to work activities), whereas informal interaction refers to personal matters (i.e., interactions that do not relate to work). The current study mainly focuses on formal interactions between employees [33-35]. However, informal interactions also impact on overall employee interactions [36], and empirical research has identified a mutually reinforcing relationship between work-related interactions and non-work-related interactions [37,38]. Frequent and positive non-work-related interactions will thus directly affect employee relationships and work interactions.

Different classifications are used to study EEI from different perspectives. Interaction is one of the most basic and common workplace phenomena, and interactions between employees can be classified based on interaction relationships or interaction methods. Employee interactions can be divided into friendly interactions and hostile interactions based on emotional relationships [39]. According to the interest relationship between employees, their interaction can be divided into cooperative interaction, competitive interaction, and conflict interaction [40]. According to the method of interaction, employee interaction can be divided into verbal interaction and non-verbal interaction, or direct interaction and indirect interaction [41,42]. The type of interaction is also different in different environments. For example, tourists entertain each other [43], customers may compete with each other [44], and guests may share information [45]. However, mutual assistance and conflict are common in various interaction scenarios. In addition, the method of interaction will influence the type of interaction. There are many methods by which employees may interact, but the main one is a direct face-to-face conversation [46]. Empirical research has found that tone of voice, attitude, body language, eye contact, and all behaviors 
associated with face-to-face conversations affect employee interactions [47]. In addition to face-to-face conversations, phone calls, emails, and even notes, are other ways by which employees may interact [48].

EEI in the workplace is mainly influenced by personal characteristics and environmental factors [48,49]. As interpersonal interaction involves psychological characteristics that affect the interaction, such as attitude and motivation, there are many in-depth studies of the psychological mechanism of interpersonal interaction [50-56]. In recent years, studies of personal characteristics affecting employee interactions have examined work motivation [50,51], gender [52], age [53,54], and personality traits $[55,56]$, all of which are found to be important factors affecting employee interactions. Empirical research finds that the personality characteristics of employees are the main factors affecting interactions among employees, and extroverted employees will have a greater number of interactions in the workplace than introverted employees [48]. Moreover, peers of similar age, with similar hobbies, and even employees with similar jobs, are found to interact more frequently than others $[48,57]$. The work environment is another factor that influences EEI. Conditions in the workplace, such as seating [58], a noisy environment [59], and even communication equipment [60], can directly impact employee interactions. In addition, workplace culture determines the degree of interaction between employees, with the potential to create a positive and happy working environment or to make employees more willing to interact [61]. Lotila (2010) argued that humane leadership could promote EEI $[62,63]$, which in turn creates mutual understanding and alleviates social pressure. Relevant research on the workplace environment proves that individuals' emotions are often affected by their workplace environment, whether positively or negatively. Such examples include workplace bullying [64], workplace encouragement [63], and workplace stress [65]. Emotional changes in employees will, in turn, affect their interactions.

EEI may have either a positive or negative impact on work attitudes, productivity, and performance $[32,66,67]$. When employees are satisfied with their interactions, they tend to perform better; for example, by reducing errors, increasing productivity, and improving customer service [68,69]. Empirical research suggests that employee interactions that have a positive impact effectively increase employees' efficiency and improve their emotional state [70]. However, the negative impact of interactions cannot be ignored. Research proves that negative communication behavior between employees affects employees' levels of happiness, and is more likely to occur when employees do not communicate directly. Negative interactions can cause confusion, anxiety, tension, and uncertainty, which can negatively impact both personal and company productivity [57].

\subsection{Chinese Factory Workers in Small and Medium-Sized Factories}

SMEs that operate factories contribute more than $60 \%$ of China's total gross domestic product (GDP) and $80 \%$ of the country's employment [71], but SME factories often lack sufficient funds to purchase advanced production machines and instead employ qualified skilled workers. Scholars believe that although the size, number of employees, and levels of capital of China's SME manufacturers are not as large as those of large-scale factories, SMEs have the advantage of better management of their factory workers [72,73].

Factory worker interaction and socialization have the potential to promote factory workers' job satisfaction and work efficiency [74]. However, limited research examines relationships between Chinese factory workers. In addition, most studies in this area only focus on the character and behavior of Chinese factory workers. Additionally, existing studies examining the mode, content, and depth of EEI may not be fully applicable to the context of FWI, because Chinese factory workers face longer working hours, higher work intensity [75], lower salaries [18], and have lower overall education levels [16] than average professions. Further, although there has been limited study of the interaction between Chinese factory workers in large-scale factories [2], the literature has not yet considered the case of workers in Chinese SME factories. Chinese factory workers' priority are wages, and they perceive workplace safety, rights, and especially interaction to be of low importance [76]. 
At present, the literature cannot clearly explain the specific form and extent of FWI in Chinese SMEs in the manufacturing industries.

\section{Methodology}

\subsection{Research Design}

The grounded theory approach, developed by Glaser and Strauss [77], seeks to explore and develop the theory associated with a studied phenomenon by means of systematic data collection and analysis. Grounded theory is primarily used to discover logic, rather than to verify logic. The qualitative inquiry using the grounded theory approach is as follows (Figure 1).

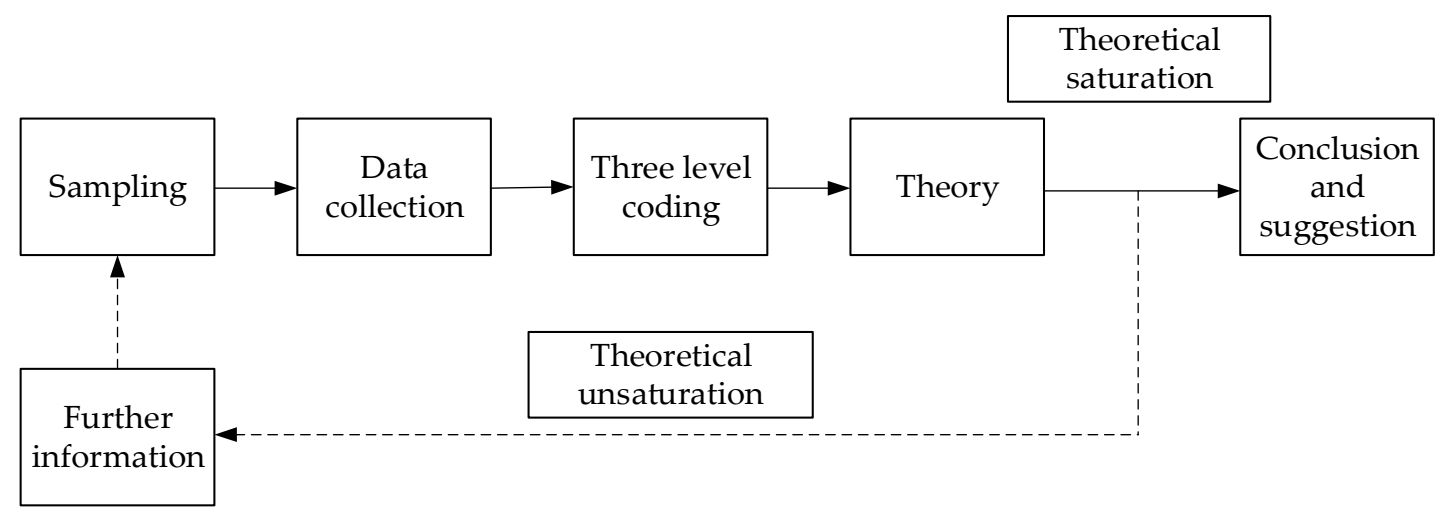

Figure 1. Flow chart using the grounded theory approach.

We adopt the grounded theory approach that has been commonly used in qualitative research to allow the systematic collection and analysis of empirical data, and it is appropriate for the present study for a number of reasons. Firstly, as the purpose of this study is to explore the nature of worker interaction in Chinese factories, a method based on assumptions would not be suitable. Secondly, the grounded theory approach is capable of extracting and summarizing the work and life experience of workers at all levels. Thirdly, the nature and formation mechanism of worker interaction in Chinese factories has not yet been studied in depth. Hence, this current study endeavors to uncover the nuances and contextual phenomenon of worker interaction from the specificity of Chinese factory workers. Fourthly, the nature and formation mechanism of worker interaction are complex and involve multiple relevant factors. As the FWI field lacks mature theories, it is reasonable to adopt the grounded theory approach in order to encapsulate other premises that may have not been previously explored.

\subsection{Data Collection}

Data used in this study include in-depth interview transcripts, interview memos, and observations of workers, all collected from a series of semi-structured interviews with 30 factory workers in Shenzhen, China, from June 2019 to August 2019. Guided procedure is appropriated to maintain the rigor of research while handling qualitative data [78,79]. The procedure is depicted as follows (Figure 2).

\subsubsection{Sampling Selection}

Taking a setting representative of China's SMEs, this study purposefully selected 30 workers in Shenzhen from a Sino-Japanese joint venture factory and a Chinese-owned factory. Shenzhen is China's third largest manufacturing center, and has more SME factories than the two larger manufacturing centers. Sino-foreign joint ventures and Chinese-owned factories are the most common forms of SME factories in China. After analyzing hundreds of articles, Thomson (2010) suggested that a researcher would perform a minimum of 25 interview sessions [80]. Thomson also highlighted the importance of the number of key informants in in-depth interviews over the number of respondents, which gives a 
reasonable approximation of the population being studied for research using the grounded theory approach. When using in-depth interviews to collect data from key informants, the emphasis is on the richness of the data, rather than the sample size. The aim is to elicit rich data to explain what is happening in the phenomenon rather than using a huge amount of repeated data $[77,80]$. Among the 30 selected workers, 25 have more than five years of work experience in different regions and different types of SME factories. Based on their ages, they can be divided into Generation X, Generation Y, and Generation Z. Participants include front-line managers, quality control (QC) workers, production line workers, and technology workers (Table 1). The selection of workers is representative of workers in SME factories in China.

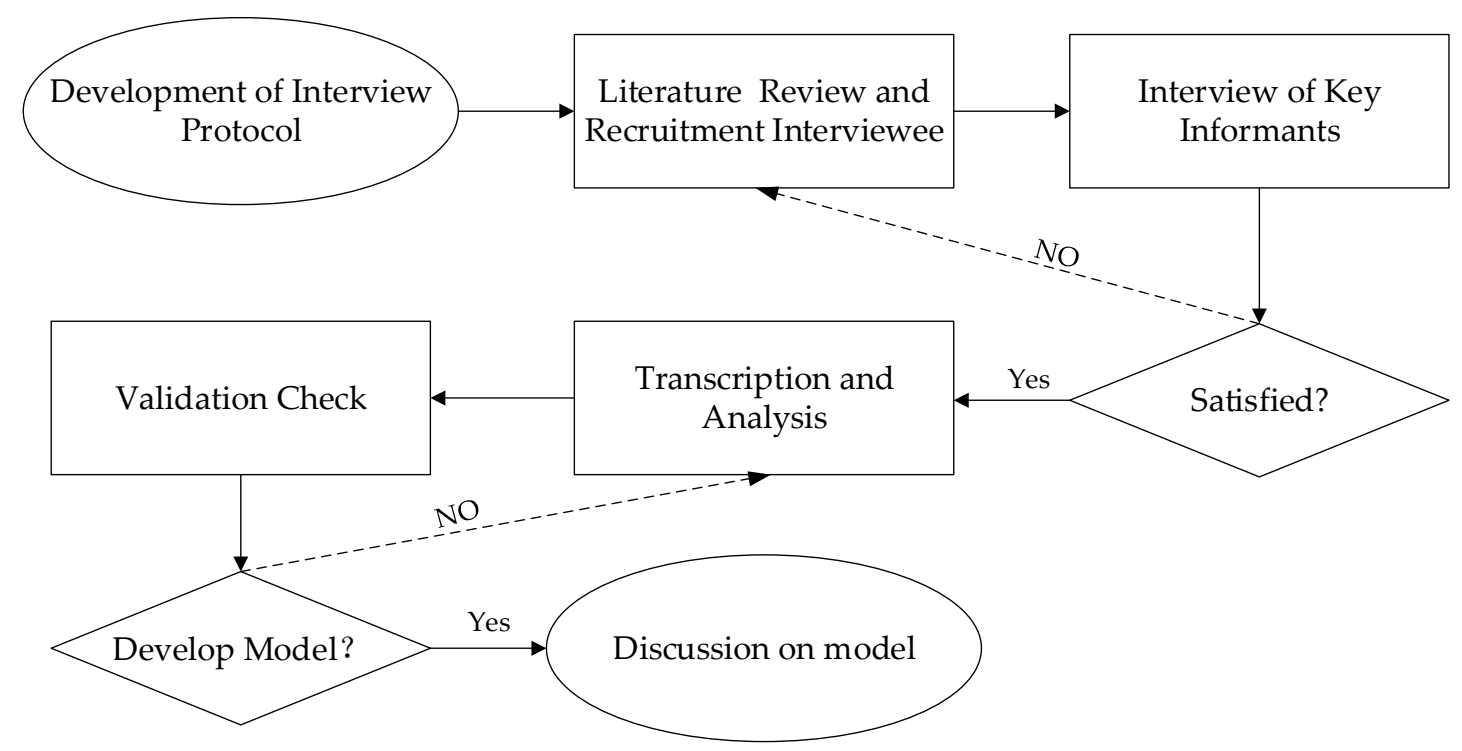

Figure 2. Flow chart of interview data collection procedures.

\subsubsection{In-Depth Interviews}

After reaching an agreement to conduct the study with factory managers and workers, we conducted in-depth interviews with the selected workers. Video cameras and semi-structured interview protocols aided all in-depth interviews. Participants' personal information has been treated as confidential. We also performed an analysis of the transcripts on an anonymous basis, and the data obtained have been used only for this study. We conducted the interview separately in a closed room to provide a confidential environment. Interviews lasted an average of $60 \mathrm{~min}$. To ensure the anonymity of participants, they are identified using the codes shown in Table 1.

Each interview began with a description of the research project. The interviewees were asked to share details of their work interaction experiences in the workplace by a facilitated discussion. Since we obtained the interviewee's basic working information from the factory's management before the interview, we followed a semi-structured interview protocol and raised some exploratory questions related to the discussion at different times based on the interviewee's specific work and personal background. Such questions enabled interviewees to recall information and experiences of their interactions in the workplace. 
Table 1. Participant profiles.

\begin{tabular}{|c|c|c|c|}
\hline Participant & Gender & Age & Type of Work \\
\hline MM1 & Male & 41 & Manager \\
\hline MF2 & Female & 28 & Manager \\
\hline MM3 & Male & 37 & Manager \\
\hline MM4 & Male & 49 & Manager \\
\hline PF1 & Female & 31 & Production line \\
\hline PF2 & Female & 34 & Production line \\
\hline PF3 & Female & 38 & Production line \\
\hline PF4 & Female & 44 & Production line \\
\hline PF5 & Female & 38 & Production line \\
\hline PF6 & Female & 35 & Production line \\
\hline PF7 & Female & 30 & Production line \\
\hline PM8 & Male & 21 & Production line \\
\hline PF9 & Female & 23 & Production line \\
\hline PF10 & Female & 27 & Production line \\
\hline PF11 & Female & 31 & Production line \\
\hline PF12 & Female & 36 & Production line \\
\hline PF13 & Female & 38 & Production line \\
\hline PF14 & Female & 20 & Production line \\
\hline PM15 & Male & 29 & Production line \\
\hline PF16 & Female & 26 & Production line \\
\hline PM17 & Male & 26 & Production line \\
\hline PM18 & Male & 47 & Production line \\
\hline PM19 & Male & 23 & Production line \\
\hline QF1 & Female & 26 & QC \\
\hline QF2 & Female & 32 & QC \\
\hline QF3 & Female & 32 & $\overline{Q C}$ \\
\hline TM1 & Male & 36 & Technology \\
\hline TM2 & Male & 45 & Technology \\
\hline TM3 & Male & 35 & Technology \\
\hline TM4 & Male & 37 & Technology \\
\hline
\end{tabular}

\subsubsection{Triangulation}

We took the general understanding that factory workers in China are usually less educated than the working population on average and workers need not touch strangers in their daily work. With this in mind, it is possible that interview participants were not good at communicating with strangers, and therefore, this was a challenge in interviewing. During the interviews, there was the possibility that information may be unclear or incomplete due to tension. Therefore, to improve the accuracy and reliability of the data, a triangulation method of verification was used. During sessions with front-line managers, we included interview questions designed to verify the answers of other factory workers. In addition, after each interview, we purposely chose to talk to the workers we were going to interview to make them less wary of us; simultaneously, we observed the working conditions and habits of the factory workers in the factory and used observational methods to verify the data.

\subsubsection{Ethical Considerations}

We first informed the management of the two factories about the purpose of the study. They wanted to obtain the objective results of our research data, and agreed to select any workers in the factory for interviews. We confirmed each participant's consent to participation to ensure that discussions were conducted on a voluntary basis. To ensure the privacy of respondents, we treated all respondents anonymously. In the final report submitted to the factory management, we only provided a text report without the name of the worker. We also did an anonymous analysis of transcripts, and the data were accessed only for this study. In order not to be affected by the factory management on the workers, 
we deliberately deleted all the names and obvious characteristics of the participants when confirming the workers' data with the factory management.

\subsection{Data Analysis}

From the interview voice recordings, we hand-crafted verbatim transcripts and entered them into Nvivo-12 software to perform data aggregation and analysis [81]. We analyzed the data through three stages as suggested by ground theory approach [77], which were open coding, axial coding, and selective coding. First of all, in open coding, we set aside personal "biases" to break down all collected data and provide them with concepts and categories. Then, in the axial coding phase, we establish links between the various parts of the data by constantly comparing and finding connections between the conceptual categories. Ultimately, in selective coding phase, after a systematic analysis of all discovered conceptual categories, we select the core categories and continue to focus on the codes associated with the core categories.

\subsection{Theoretical Saturation Test}

The grounded theory approach requires researchers to collect and analyze data continuously as well as to supplement and improve the emergent concepts and categories consistently [79]. When newly collected data cannot be classified, this indicates that the theory has reached saturation. We first used the data from 25 interviews for coding. After selective coding was completed, we encoded the data from the remaining five interviews in three levels of coding and found that no new categories were generated. In addition, we fed back the categories and models produced by the coding to factory management and some interviewees. They confirmed that they believed the model to be consistent with the workers' situation, and did not deem it to need any new categories. As no new categories were found, new data collection was stopped.

\section{Findings}

\subsection{Open Coding}

The purpose of open coding is to develop a large amount of code to describe, name, or classify events [77]. Using open coding, we categorized interviews, memos, and observations. We summarized all the data into 14 initial classifications. An example of this open coding is shown in Table 2.

Table 2. Open coding of the factory worker to factory worker interaction (excerpt).

\begin{tabular}{|c|c|c|}
\hline Original Data & Labeling & Initial Categories \\
\hline $\begin{array}{l}\text { When my workmate has an emergency, goes out to answer the phone, or goes to } \\
\text { the toilet, a less busy workmate will replace them at their assembly line position } \\
\text { until they return. } \\
\text { We always help each other by substituting positions, and sometimes the monitor } \\
\text { will help us. }\end{array}$ & Substitute & \multirow{4}{*}{ Mutual assistance } \\
\hline $\begin{array}{l}\text { Whenever we see newcomers, our workmates take the initiative to help them } \\
\text { when they are relatively free. Teaching newcomers the skills we have } \\
\text { accumulated over the years gives a sense of accomplishment. Newcomers need } \\
\text { our help, otherwise, they will be lost. }\end{array}$ & Help new workers & \\
\hline $\begin{array}{l}\text { The speed of the machine is usually faster than our processing speed, and if we } \\
\text { are a little slower, we will accumulate many products on the machine. After } \\
\text { completing our tasks, we help others to make it less difficult. If other people } \\
\text { accumulate many products, there will be pressure, and the team leader will scold } \\
\text { us when they see it. }\end{array}$ & Help others & \\
\hline $\begin{array}{l}\text { Sharing your skills with others can make the factory more efficient. } \\
\text { Everyone has their own way of dealing with products, communicating with } \\
\text { others to learn from them, and then develop their own methods. } \\
\text { I would like to share my methods with others. I can chat with others and learn } \\
\text { from them. }\end{array}$ & Share skills & \\
\hline
\end{tabular}




\subsection{Axial Coding}

Axial coding is the process of classifying and abstracting the first categories identified by open coding into the main categories by exploring the inherent relationships between categories [77]. In axial coding, we divided 14 initial categories into six main categories: Interaction, Individual characteristics, External environment factors, Production efficiency change, Supervisor style, and States and emotions (Table 3).

Table 3. Axial coding of the factory worker to factory worker interactions.

\begin{tabular}{|c|c|c|}
\hline Core Categories & Conceptualization & Dimensions \\
\hline \multirow{3}{*}{ Interaction } & Mutual assistance & $\begin{array}{c}\text { Substitute, Help newcomers, Help workmates, } \\
\text { Share skills }\end{array}$ \\
\hline & Information share & $\begin{array}{l}\text { Gossip, Job opportunities, Personal information, } \\
\text { Technology skills, News }\end{array}$ \\
\hline & Conflict & Comparison, Arguments, Jealousy \\
\hline \multirow{5}{*}{ Individual characteristics } & Personality & $\begin{array}{l}\text { Humor, Unsociable, Serious, Talkative, } \\
\text { Optimistic, Pessimistic }\end{array}$ \\
\hline & Background & $\begin{array}{l}\text { Older, Younger, Peer, Family background, Children, } \\
\text { Self-situation }\end{array}$ \\
\hline & Work motivation & Pass the time, Make money, Learning experience \\
\hline & Experience & Work experience, Life experience \\
\hline & Relationship & Hometown fellow, Relative, Friend \\
\hline \multirow{3}{*}{ External environment factors } & Type of work & QC, Technology, Manager, Production line \\
\hline & Work time & Day shift, Night shift, Weekend \\
\hline & Factory state & Busy, Normal \\
\hline \multicolumn{2}{|c|}{ Production efficiency change } & Increase, Decrease \\
\hline \multicolumn{2}{|c|}{ Manager style } & $\begin{array}{l}\text { Monitor character, Relaxed management, Strict } \\
\text { management, Senior management requirement }\end{array}$ \\
\hline \multicolumn{2}{|c|}{ Emotional state } & Regular interaction, Desire interaction, Reject interaction \\
\hline
\end{tabular}

\subsection{Selective Coding}

Selective coding is the process of selecting one category as the core category and examining the association of every other category with that category [77]. Using selective coding, all sub-categories are re-examined, and the connections between them are used to build the study model.

\section{Result}

\subsection{Types of FWI}

There are three main types of interaction between factory workers in the workplace: mutual assistance, conflicts, and information sharing.

\subsubsection{Mutual Assistance}

Helping each other in the workplace is a form of assistance that is spontaneous and does not require anything in return. Factory workers spend more than $12 \mathrm{~h}$ a day in the workplace; older factory workers often describe the production workplace as a "second home", and workmates are more like relatives. In addition, many factories pay hourly wages at rates that change with the financial performance of the factory, which creates an incentive for factory workers to increase their overall efficiency, because this will cause their wages to increase. In such an environment, factory workers are more likely to support one another, in both behavior and spirit.

Mutual assistance among factory workers mainly includes substituting, helping newcomers, helping workmates, and sharing skills. These mutual assistance behaviors will help to build good 
relationships between factory workers: "When my workmate has an emergency, goes out to answer the phone, or goes to the toilet, a less busy workmate will replace them at their assembly line position until they return" (PF13); "We always help each other by substituting positions, and sometimes the monitor will help us" (PF11). In addition to substituting for each other in the event of an emergency, factory workers are also happy to help new workers integrate into their "home." In addition to the work skills shared with newcomers, they talk to them about trivial matters in their lives to ensure they can relax and work: "I came to work in this factory more than ten years ago; when I was a newcomer, my workmates around me also kept helping me" (PF4). Different factory workers have different skills to more effectively perform seemingly simple actions: "Sharing skills with others can better improve the efficiency of our factory" (PF7); "Everyone has their own way to deal with products, communicate with others to learn from others, and then develop their own methods" (PF9); "I would like to share my methods with others. I can chat with others and learn from others" (PF6). In a nutshell, factory workers help one another and establish a secure emotional connection, making workers feel "at home" in the factory.

\subsubsection{Conflicts}

The factory workers talk about many different topics in random conversation. Sometimes, the conversation may be seen as showing off and may cause dissatisfaction due to differences in the family conditions of individual workers: "I do not like that workmate who is always telling me how her son is, because my child is not doing well in school" (PF14); "She always tells us what she bought last weekend, which is obviously to show off to me, I do not like it" (PF6). According to our interviews, this behavior of flaunting tangible or material success, alongside with different views on certain matters can lead to conflicts among factory workers.

\subsubsection{Information Share}

Sharing information is the most frequent type of interaction among factory workers. In particular, the factory workers like to gossip about workmates in the factory: "Gossip makes me feel happy" (PF6); "Gossip can satisfy my curiosity" (PF16); "Gossip enables me to know more about the personality of workmates in the factory" (PF1). In addition to gossip, factory workers with children like to share information about their children with workmates, such as their test results and their work achievements: "My child makes me proud and happy, and I want to share it with others" (PF3). Many young factory workers share job information, compare wage differences and seek to improve their promotion or life development: "From other people, you can learn the promotion opportunities and wages in other factories, and you can find a direction for yourself" (PF14). Older factory workers typically do not plan to change jobs; they commonly share current affairs information: "I am very concerned about the country's policy on SME factories; if the factory industry shifts, we may have to move or be unemployed" (PM18).

\subsection{Drivers of FWI}

Both individual characteristics and external environmental factors affect the interaction between factory workers. Individual characteristics include personality, background, work motivation, experience, and relationships. External environment factors include the type of work, work time, and factory status.

\subsubsection{Individual Characteristics}

From our interviews, personality appears to be one of the most critical factors influencing factory worker interaction. Extroverted factory workers are more likely to make friends and to interact more frequently than introverted factory workers: "I like chatting with cheerful people, which also makes me happy" (PF10); "Chat with optimistic coworkers will make me more optimistic" (PM19); "I would rather be dazed than talk to those who are introverted" (TM3). 
The personal background is another factor that affects employee interaction. Factory workers with substantial age differences usually only have work-related interactions and no non-work-related interactions. They believe the age gap is the reason for the lack of non-work-related topics: "I do not know what I can talk to them about, their children are older than me" (PF14); "I have different ideas to them, which may be because I am much older than them, and it is easy to provoke conflict when chatting" (PM18). Factory workers who have raised children often find themselves talking about their children, but factory workers without children may dislike the topic: "I do not think I can communicate with them, they are almost all discussing their children, but I have no experience raising children" (PF14).

Differences in motivations also affect interactions between factory workers. The three main motivations for factory workers to work are to make money to support their family, to pass the time, and as a learning experience. Factory workers who work to make money to support their families are consistently found to have fewer interactions than other workmates. These workers and factory workers who want to gain experience both prefer more work-related interaction and less chat: "The goal of my job is to make money; when the top manager knows I am more efficient than other workmates, I will have the opportunity to be promoted to the monitor and make more money" (TM3); "I work here for my own better development in the future; chatting does not help me acquire skills, it only improves the relationship with workmates" (TM1). Factory workers who work to pass the time represent more than one-third of our interviewees. Most of these factory workers are older, with children who already go out to work and without excessive pressure in their lives: "I have been working here for more than 15 years ... If I stop working, I will be bored ... My children give me money every month. Here I can not only find someone to chat with but also earn a salary-I am happy here" (PF4).

Factory workers with a rich life and work experience attract other workmates and increase interaction among factory workers. For example, PF9 said, "I prefer to chat with those workmates who have rich experience in life: they tell me a lot of interesting things"; PM19 said, "I can learn from other workmates who frequently change jobs to determine whether I need to change jobs."

From our interviews, the most crucial factor affecting interaction appears to be the relationship between workers, and the main types of relationships are relatives, hometown fellows, and friends. Factory workers with relatives consistently report chatting to them about a larger number of different topics, and more frequently help each other: "I work here because my parents both work here. Working here will give me more opportunities to talk to them" (PM15); "My brother works here. He said the salary is good here. I believe in my brother, so I am working here" (TM4). Hometown fellows interact more because factory workers who grew up in the same area share similar dialects and tend to have more similar lifestyles: "I am a minority, I do not speak Mandarin very well ... I only speak with my hometown fellow villagers in our Buyi language" (Buyi nationality is one of the minorities in China and has a unique language) (QF3). Most factory workers can make good friends in the workplace, and the relationship between friends also promotes more frequent interactions between factory workers: "The reason I came here to work is because of my good friend, he introduced me to work here. Although we have different types of work, we usually talk when we meet in the workshop" (PF1). Factory workers are usually more willing to interact with people with whom they have a closer relationship, whether for work-related interactions or non-work-related interactions, and are comparatively reserved with strangers.

\subsubsection{External Environment Factors}

The type of work undertaken will have a meaningful impact on whether factory workers need to interact with others actively. The nature of the job roles of QC workers and technology workers means that they have to take the initiative in having work-related interactions with workers on the production line: "I know everyone here, I have to spot check their products on the production line every day, and I need to tell them about the reduced defects" (QF2); "I have to debug the machine every day constantly; if the production workers find that the machine is abnormal, they will also ask me to look 
for problems" (TM2). The interaction between factory workers on the production line is relatively infrequent compared to other types of work in the factory. As PM17 said, "The production line cannot be stopped, and our locations are separated, the machines are noisy, and speech is inaudible." Managers have the most work-related interaction among the front-line workers in the factory, and their daily work is interactive by its nature: "My job is to balance and coordinate the factory workers here, and I need to maintain good communication with them so that the factory production can proceed as normal" (MM1); "I need to keep in touch with QC staff, and I also need to communicate with technical workers: there are all kinds of emergencies every day, and things they cannot handle need to be handled by me" (MM3).

Factory workers' working time can be divided into day shifts and night shifts, both of which last for more than $12 \mathrm{~h}$ per day, even on weekends. Interactions between factory workers are characterized differently at three different times of the day. Day shifts on weekdays are often subject to unscheduled inspections by senior managers and customers visiting production workshops, and factory workers on day shifts generally only have work interaction: "Day shifts are harder when the senior manager sees we are chatting, our salary will be deducted" (PM18); "As long as the senior managers are working at the factory, we dare not talk, and I do not know why, anyway, nobody speaks" (TM3). On night shifts and weekend shifts, workers generally do not encounter senior manager inspections or visiting customers. These shifts are also the best times for factory worker interaction, whether work-related or non-work-related: "Despite the hard work of the night shift, the rules may be easier than on the day shift" (PF10); "Weekend pay is high, and there are more opportunities to chat with workmates-I like to work on weekends" (PF4); "It is difficult to manage workers when senior managers are not here, but factory workers are basically able to keep on working" (MF2).

Order instability is a common problem in SME factories, and factory workers must sometimes work overtime to produce goods to meet urgent orders: "We have to work overtime to check the quality of the product, and we do not have the opportunity to chat" (QF2); "Urgent orders are terrible, you will be scolded a little by the squad leader when you go to the toilet" (PF9). When the factory is short of orders, although factory workers interact more than usual, they also worry about their future: "Whenever I encounter a shortage of factory orders, I am afraid of losing my job" (PF5); "When we were short of orders, more of the topic of conversation was worrying about our product quality and losing customers" (PF4).

\subsection{Conditions Affecting FWI}

Conditions that affect factory worker interaction include the emotional states of workmates and the management style of managers. PF7 said, "When a workmate is in a bad mood, we usually simply comfort her and wait until her mood is restored before talking to her." Relatedly, PF13 said that, "Sometimes watching a workmate who is happy, I know there must be something to share with us." The emotional state of workmates determines whether they can interact effectively. In addition to the emotional state of workmates, the management style of managers will increase or decrease the interaction between factory workers: "Our squad leader does not like gossip, we can only talk to her about the work ... She will be unhappy if she finds that we are gossiping" (PF14); "The squad leader of the other shifts allow chatting while they remain efficient, but our squad leader does not" (PF10); "Sometimes important guests come to visit the factory, and the manager tells us that we are not allowed to speak at the workplace, even if we encounter work problems, we need to wait until the guests leave" (TM2).

\subsection{Influence of FWI}

As factory workers interact, their productivity changes. Especially after non-work-related interactions, factory workers believe their productivity has improved: "I feel that when I am in a good mood, my work will be faster and easier" (PF7); "Long hours of work will be boring; when you talk during night shifts, everyone will work with greater mental alertness" (PF11). Factory workers 
generally think that interactions, especially non-work-related interactions, can maintain a good mood and improve their productivity. The vast majority of assembly line workers like to interact and are eager to interact in the workplace and believe that the effect of interaction is positive. Nonetheless, there is still a small percentage of workers who are unable to accept that work interaction is effective in boosting their productivity. Even they point out that minor interaction will interrupt the work and make it difficult to concentrate. After validating the data with HR managers, we found that this small group of workers is usually unpopular and not welcomed by the team. However, front-line managers do not think that factory worker interactions will necessarily have a positive impact: "The output of the day shift is basically stable, but the night shift is always changing, and sometimes the workers just forget to work while chatting" (MM3); "Sometimes workmates are unhappy after chatting, which causes our productivity to drop" (MM4); "At first I also thought that those skilled workers were talking about technology during working hours, but in the end I found that they were chatting, not working or studying" (MM3). These data indicated that chatting can have negative impact to FWI as well as productivity, depending on the nature and topic of the interactions.

\subsection{Model of FWI}

As shown in Figure 3, this research enables us to develop a model of FWI in the workplace using the grounded theory approach [79]. The model explains the types of FWI in the workplace, their formation process, and their influence. Interaction is the core of the model and includes mutual assistance, conflict, and information sharing. Individual characteristics and external environment factors are influencers of factory worker interaction in the workplace. Individual characteristics include personality, background, work motivation, experience, and relationships. External environment factors include the type of work, work time, and factory state. In addition, the management style of managers and the emotional state of factory workers directly affect FWI in the workplace. Finally, the model incorporates the impact of FWI on productivity.

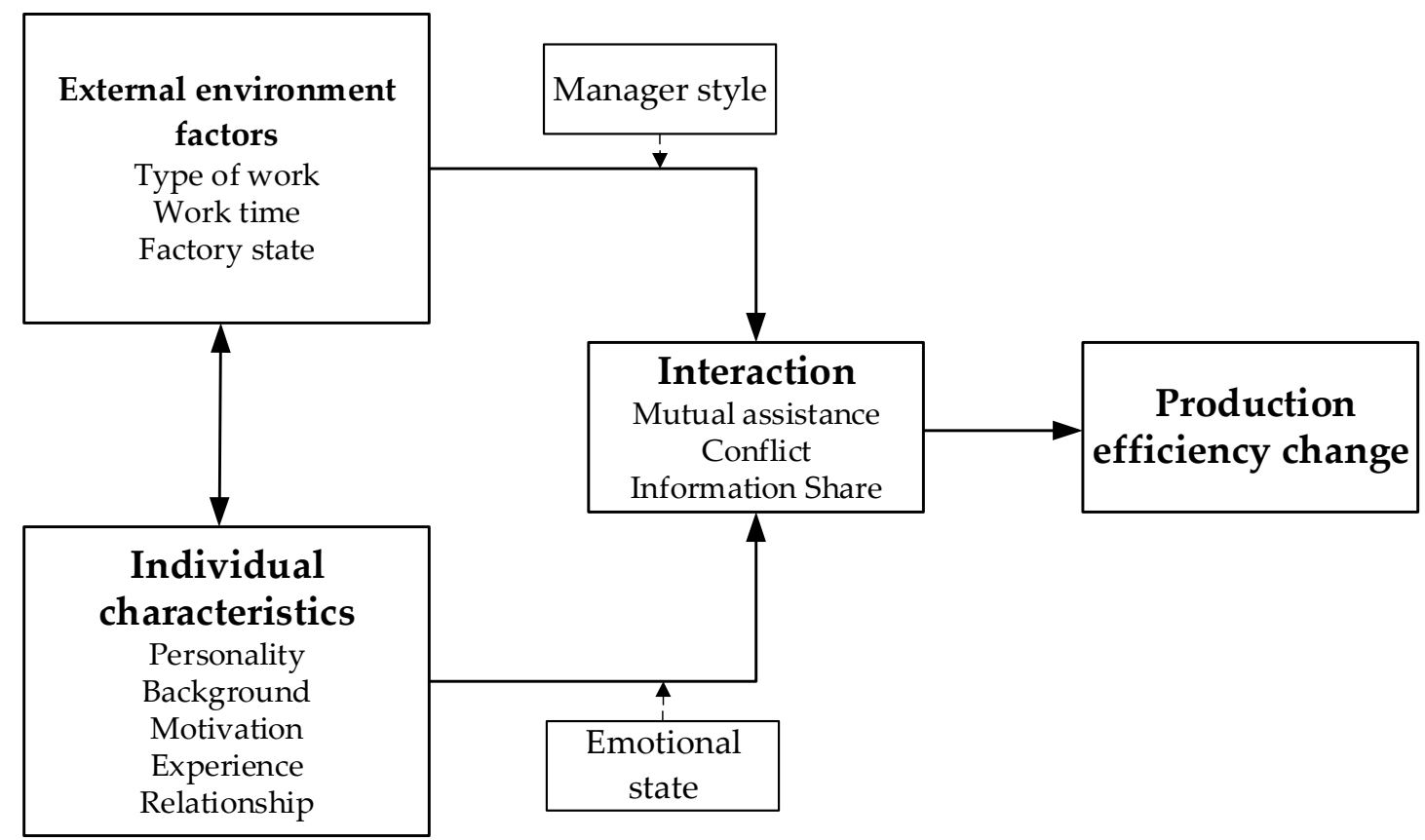

Figure 3. An integrative understanding of factory workers' interactions.

\section{Discussion}

Studying the interaction between individuals has brought the emphasis on environmental impact and aspect [82], meaning that the environmental context profoundly influences the interactions between 
individuals. This study extends early work by accentuating the ways and reasons for the interactions of workers in SME factories based on 30 workers in China through the grounded theory approach, as such a phenomenon requires more scrutiny across different contexts.

FWI in this model is determined by both individual characteristics and external environmental factors. As observed in previous studies, all individuals have personality traits of some kind, and these will inevitably affect active or passive interactions with others [49]. In addition, existing relationships are the main reason for interaction between individuals, which is consistent with the fact that most people are more inclined to interact with people they know than strangers. People with similar backgrounds are more likely to interact, such as those with similar age, shared hometowns, and similar life experiences $[48,49]$. The emotional state of individuals and the management style of managers have significant moderating effects in the FWI model. The premise of these interactions is that external environmental factors and individual characteristics can actively promote interaction. Although any particular kind of interaction can exist in the context of different individual emotions, in general, emotional states will limit or promote interaction $[83,84]$. The management style of managers is a more direct way to restrict or promote factory worker interaction [48].

Our finding shows that workers are mostly eager to interact in the workplace, especially non-work interactions. Workers believe that interaction not only maintains a good emotional state but also improves productivity effectively, as indicated by past work [85]. Nevertheless, front-line managers have opposite views of workplace interactions. In particular to this current study's findings, they argued that the degree of worker interaction is difficult to control and evaluate, while the interactions would progressively move from work-related matters to immaterial chatting or even gossip, ultimately affecting their productivity.

Taking information sharing as the ultimate goal is the discovery of interaction research in this study. However, the significance of information sharing in this study is not limited to the practical function of delivering work-related information. More specifically, sharing information among workers in SMEs' factories mostly reflects gossip, job opportunities, personal life, technical skills, and news sharing. The information sharing of the worker interaction provides mutual social amusement, reduces stress at work and increases productivity, as well as reduces conflict, and increases mutual assistance to build a strong sense of family harmony in the factory. Furthermore, while the degree of interaction among workers is related to personal characteristics, the style of the management directly affects worker interaction.

This study extends the theory of interactions to the context of Chinese SME factories. The study showed that there are related contradictions between the worker demand for worker interaction and the operational goal for SME factories of maximizing profits. Even if factory workers' interactive behavior can meet the communication needs of workers and improve their work pleasure, the negative impact on workers of the non-work information sharing is equally strong. The management group has the tendency to view Chinese workers as generally lacking in self-discipline in workplaces. For them, interactions without restrictions and rules will decrease workers' concentration and workplace interaction cannot guarantee increased productivity. This is the opposite of China's SME factories of pursuing short-term interests, also reiterating the military style management advantages of China's large factories [1]. In the current situation where the degree of interaction has not been clearly studied, although the interaction between workers cannot ensure a direct benefit to small and medium-sized factories, it may even reduce production efficiency. Still, FWI can meet the needs of workers at work. Although workers in an interview stressed the significance of worker interaction, in particular with regard to information sharing, none of those interviewed mentioned that they needed or suggested that factory management should enable them to interact in the workplace. The unequal relationship between workers and factories is determined by the characteristics of workers in the context of Chinese society $[86,87]$. Young workers have, however, generally stated that they would prefer work in a relaxed environment if there is no significant wage difference, meaning that worker interaction does not improve organizational performance directly. Nevertheless, it can help SME factories more readily 
recruit and retain young workers who are the leading and sustainable force in factories. When a larger sample size and the time passes (i.e., more new generations replace the old generation as the main workforce of the factory), the results should highlight the importance and superiority of the interaction between workers in SME factories. More future work is needed to identify the nature of the work environment that could foster happiness gained through FWI, and how to systematically bring this change into the Chinese SME factories.

Furthermore, SMEs have limited their HRM practices to the level of imitation of larger enterprises. This imitation, however, ignores the uniqueness and complexity of the hard to understand HRM of SMEs. We have noticed that the HRM model of an enterprise is a dynamic process, and during its development, the enterprise continually adjusts its own HRM model [88]. This implies that the simple imitation of interactive management of HRM practice of large factories can enable SME factories to reduce the costs of managerial resources, but cannot, because of the differences in capital and resources, lead to a similar effect for HRM in SME factories than for large factories [89]. In general, increase worker interaction is of considerable significance to HRM practice in SME factories. Worker interaction in the workplace may not directly benefit small and medium-sized factories, such as increasing productivity, but properly liberalizing the interaction between workers is more conducive to workers' increased satisfaction with their job and to gain future sustainable development.

\section{Conclusions}

Through the grounded theory approach employed in studying FWI in Chinese SME factories, we develop a model of worker interaction to depict the type, driving factors, and influential outcomes. Worker interaction is primarily affected by the personal character and external factors, taking information sharing as the ultimate goal in this study, including the moderating role of worker's emotional state and management style. We discover that worker interaction in the workplace, especially non-work interactions, are effective in improving efficiency, but, in the meantime, excessive interactions can bring negative consequences. SME factories merely imitate large-scale factories that prohibit worker interaction in the workplace, and may lose the advantage of improving production efficiency through worker interaction. Although allowing worker interaction does not necessarily lead to immediate positive outcomes, we believe that worker interaction can bring sustainable development to SME factories. First, managers can control the degree of interaction of workers in the factory. Controlling the extent of workers' interactions effectively can improve the factory's production efficiency and improve the factory's current competitiveness and sustainable development capabilities. Second, the interaction of workers is unpredictable, which may reduce the efficiency of the output. Nonetheless, from the viewpoint of workers as the key assets of the factory, although interaction may temporarily reduce the productivity, it can bring sustainable labor resources to the factory (i.e., making it easier to attract young workers) and it is more conducive to the sustainable development of SME factories (Figure 4).

Theoretically, the FWI model produced in this study has verified the relevance to Chinese SME factories of the two types of interpersonal interaction of mutual assistance and conflict. This research fills the theoretical gap that is overlooked in Chinese SME factories. Specifically, our paper enriches the theory in the field of interpersonal interaction. Our finding shows that appropriate interaction between workers not only maintain the worker's morale, but also create a pleasant working environment and enhance the worker's sense of belongingness. Through this, the factory workers would then develop some sense of viewing their workplace not only as a place to get income, but also as a sanctuary to further their self-esteem and feelings of co-sharing in both emotions and self-development.

Additionally, information sharing is presented as a new type of interpersonal interaction relevant to SME factories. Information sharing can improve workers' production efficiency. Nevertheless, this aspect has been neglected in research, especially in a mechanistic and military-like factory work environment. Hopefully, this study provides a new theoretical perspective for HRM practice in SME factories, particularly in explaining interpersonal interaction. 


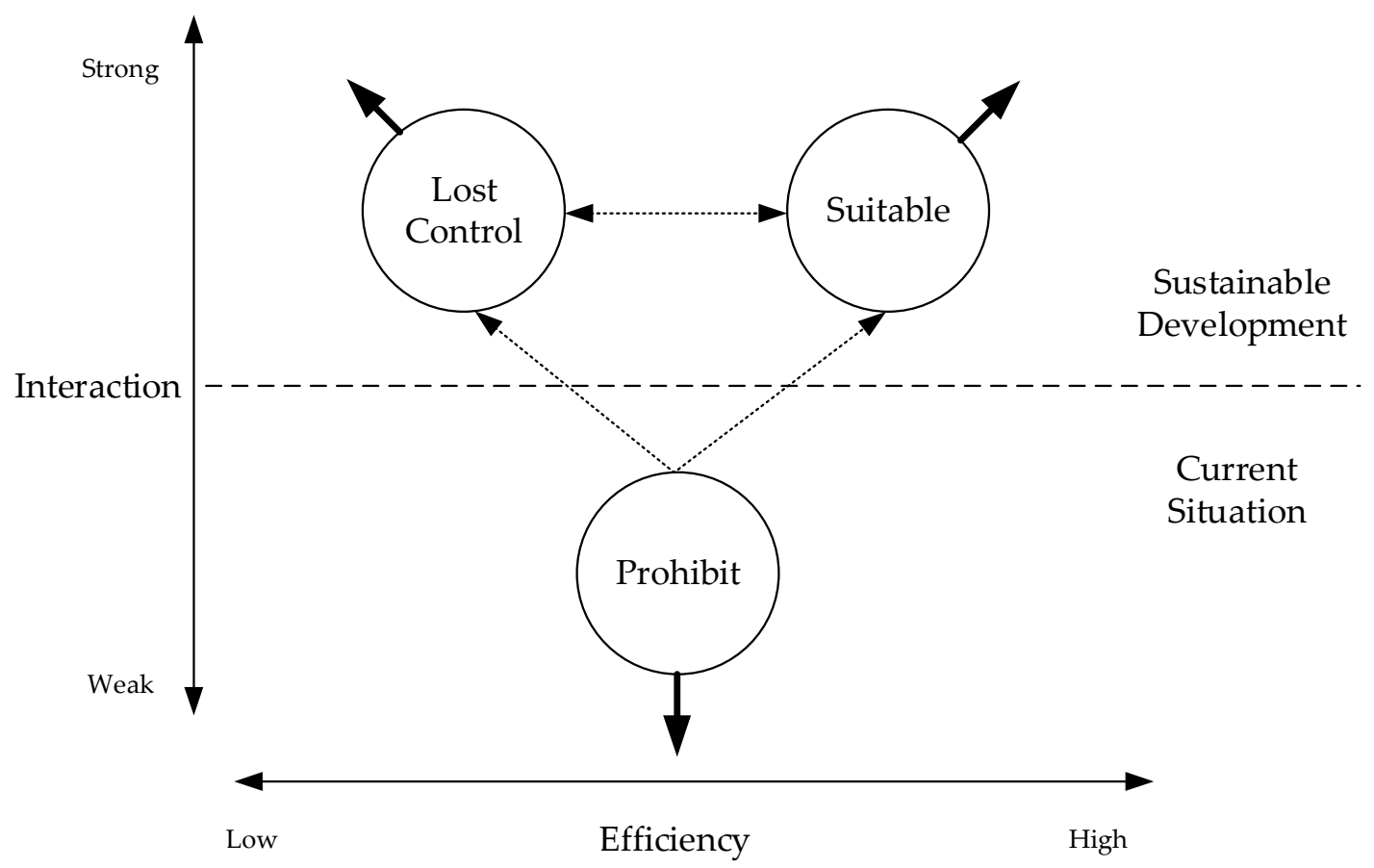

Figure 4. Overview of worker interaction.

From the managerial perspective, this study provides some enlightenment to emerging economies that are developing its manufacturing industry. In terms of HRM, blindly copying the management mode of large enterprises of other contexts may ignore the advantages of SME factories of specific contexts that have their own consistencies and nuances of local requirements and challenges for sustainable development. For China, the military-style Taylorist management can effectively guarantee a certain level of production efficiency for the factory, but this management style will make workers lose the pleasure of work. Under military-style management, senior managers and owners tend to neglect the positive effects of factory worker interactions to improve work efficiency. Elements and practices that allow fostering appropriate FWI are crucial. This includes providing the factory workers with opportunities to interact as much as possible, such as sessions for skills sharing, emotional intelligence upgrades, and teambuilding; while still ensuring that they maintain work efficiency could provide further meaningful work life. The results of this study hopefully could shed further interest and light to the process of understanding the impact of factory workers in third world countries such as India, Vietnam and Pakistan. Although restrictive worker interaction in the workplace can promote efficient factory operations during the early growth period, as factories gradually grow closer to developed countries, restricting interaction between workers may limits SMEs to achieve sustainable competitive advantage.

This study has certain limitations, most of which revolve around the theoretically selected sample. The model is based on specific data from interviews with Chinese workers, which limits the generality of the framework application. We believe that the lack of interaction among Chinese workers is related to China's unique national culture. For instance, China is a high-power distance country, and Chinese workers are more likely to accept unequal treatment; they can give up their basic rights at work in order to maintain their jobs. This phenomenon may occur in some emerging economies in the vicinity of China, which are also affected by Eastern culture. For future study, consideration should be given to the national culture perspective, in particular, power distancing factors when using this framework. The uniqueness of enterprises in different regions are potentially affected by the unique characteristics of their social environments, production environments, internal environment of an enterprise, the type of factory and the type of employee. Such limitations could compromise the generalizability and versatility of the present findings to all SMEs in China. Therefore, future research should continue 
to investigate the mechanism and contextual factors of workers' interaction in different regions and cultures of SME factories. On the other hand, we also suggest future researchers to further explore FWI through enhancement of the methodology used in this current work. We employ a qualitative methodology to construct the FWI model, which can be extended into applying the quantitative or mixed-methods approach in order to test the constructs and the relationships in the model [78].

Finally, this work on FWI hopefully could further develop trajectories for the concept to flourish. It is because SME factories across industries would remain critical in many regions. Research in FWI would generate opportunities for cross border comparison and may contribute to future management practices of SME factories in new conditions such as the post COVID-19 pandemic. In the context of the global pandemic of COVID-19, social distancing has somewhat limited worker interactions. Future research could further explore and focus on changes in worker interaction patterns during outbreaks.

Author Contributions: Conceptualization, Y.Y. and R.O.; methodology, Y.Y.; software, Y.Y.; validation, Y.Y., R.O. and B.N.; formal analysis, Y.Y. and H.T; investigation, Y.Y. and B.N.; data curation, Y.Y.; writing—original draft preparation, Y.Y. and B.N.; writing-review and editing, H.T.; visualization, R.O.; supervision, R.O. All authors have read and agreed to the published version of the manuscript.

Funding: This research received no external funding.

Conflicts of Interest: The authors declare no conflict of interest.

\section{References}

1. Pun, N.; Shen, Y.; Guo, Y.; Lu, H.; Chan, J.; Selden, M. Apple, Foxconn, and Chinese workers' struggles from a global labor perspective. Inter Asia Cult. Stud. 2016, 17, 166-185. [CrossRef]

2. Lüthje, B.; Butollo, F. Why the Foxconn model does not die: Production networks and labour relations in the IT industry in South China. Globalizations 2017, 14, 216-231. [CrossRef]

3. Sung, Y.-W. Made in China: From world sweatshop to a global manufacturing center? Asian Econ. Pap. 2007, 6, 43-72. [CrossRef]

4. Xu, K.; Li, W. An ethical stakeholder approach to crisis communication: A case study of Foxconn's 2010 employee suicide crisis. J. Bus. Ethics 2013, 117, 371-386. [CrossRef]

5. Ren, H.; Zhou, S.; Hu, A.; Cheng, H. Industrial Robots and Jobs Turnover: Evidence from Chinese Firm Level Data; Social Science Research Network: Rochester, NY, USA, 2018.

6. Hewett, S.; Becker, K.; Bish, A. Blended workplace learning: The value of human interaction. Educ. Train. 2019, 61, 2-16. [CrossRef]

7. Harney, B.; Alkhalaf, H. A quarter-century review of HRM in small and medium-sized enterprises: Capturing what we know, exploring where we need to go. Hum. Resour. Manag. 2020. [CrossRef]

8. Harney, B.; Dundon, T. Capturing complexity: Developing an integrated approach to analysing HRM in SMEs. Hum. Resour. Manag. J. 2006, 16, 48-73. [CrossRef]

9. Graham, K.A.; Dust, S.B.; Ziegert, J.C. Supervisor-employee power distance incompatibility, gender similarity, and relationship conflict: A test of interpersonal interaction theory. J. Appl. Psychol. 2018, 103, 334. [CrossRef]

10. Lee, K.; Chae, Y.J.; Shin, I. Motivational antecedents of leader-member exchange differentiation: Evidence from South Korea. Asia Pac. J. Manag. 2016, 33, 87-112. [CrossRef]

11. Huang, C.-Y.; Weng, R.-H.; Chen, Y.-T. Investigating the relationship among transformational leadership, interpersonal interaction and mentoring functions. J. Clin. Nurs. 2016, 25, 2144-2155. [CrossRef]

12. Cunningham, L.X.; Rowley, C. Small and medium-sized enterprises in China: A literature review, human resource management and suggestions for further research. Asia Pac. Bus. Rev. 2010, 16, 319-337. [CrossRef]

13. Raven, B.H. The bases of power and the power/interaction model of interpersonal influence. Anal. Soc. Issues Public Policy 2008, 8, 1-22. [CrossRef]

14. Coté, S. A social interaction model of the effects of emotion regulation on work strain. Acad. Manag. Rev. 2005, 30, 509-530. [CrossRef]

15. Wang, C.-H.; Varma, A. A process model of how interpersonal interaction leads to effectiveness of the expatriate-host country national relationship. Cross Cult. Strat. Manag. 2018. [CrossRef]

16. Chen, D.; Guan, J. How Education Level, Gender, and Social Network Correlate With Migrant Workers' Starting Income in China's Urban Cities. US China Educ. Rev. 2016, 6, 63-70. 
17. Chen, S.-C.; Jiang, W.; Ma, Y. Decent work in a transition economy: An empirical study of employees in China. Technol. Soc. Chang. 2020, 153, 119947. [CrossRef]

18. An, F.; Broadbent, K.; Yuan, F. Employment inequality among women migrant workers in China: Comparative analysis from the 2014 Guangdong Migrant Workers Survey. Asia Pac. J. Hum. Resour. 2018, 56, 518-538. [CrossRef]

19. Binh, T.T.C.; Linh, N.M. Human resource management for innovation in Vietnam's electronics industry. Asian J. Technol. Innov. 2017, 25, 345-366. [CrossRef]

20. Hossain, G.; Mahmood, M. Employee Turnover in the Garment Industry in Bangladesh: An Organization-level Perspective. South Asian J. Hum. Resour. Manag. 2018, 5, 129-149. [CrossRef]

21. Choi, J.H.; Kim, S.; Yang, D.-H. Small and medium enterprises and the relation between social performance and financial performance: Empirical evidence from Korea. Sustainability 2018, 10, 1816. [CrossRef]

22. Rahiman, M.H.U.; Kodikal, R. Impact of employee work related attitudes on job performance. Br. J. Econ. Financ. Manag. Sci. 2017, 13, 93-105.

23. Menon, S.; Shah, S.; Coutroubis, A. Impacts of I4. 0 on sustainable manufacturing to achieve competitive advantage. In Proceedings of the International Conference on Operations and Supply Chain Management (OSCM 2018), Cranfield, UK, 9-12 September 2018; pp. 379-387.

24. Kumar, V.; Pansari, A. Competitive advantage through engagement. J. Mark. Res. 2016, 53, 497-514. [CrossRef]

25. Qiu, L.; Jie, X.; Wang, Y.; Zhao, M. Green product innovation, green dynamic capability, and competitive advantage: Evidence from Chinese manufacturing enterprises. Corp. Soc. Responsib. Environ. Manag. 2020, 27, 146-165. [CrossRef]

26. Quaye, D.; Mensah, I. Marketing innovation and sustainable competitive advantage of manufacturing SMEs in Ghana. Manag. Decis. 2019. [CrossRef]

27. Haynes, B.; Suckley, L.; Nunnington, N. Workplace productivity and office type. J. Corp. Real Estate 2017, 19, 111-138. [CrossRef]

28. Kostka, G.; Moslener, U.; Andreas, J. Barriers to increasing energy efficiency: Evidence from small-and medium-sized enterprises in China. J. Clean. Prod. 2013, 57, 59-68. [CrossRef]

29. Berger, C.R.; Calabrese, R.J. Some explorations in initial interaction and beyond: Toward a developmental theory of interpersonal communication. Hum. Commun. Res. 1974, 1, 99-112. [CrossRef]

30. Heath, C.; Knoblauch, H.; Luff, P. Technology and social interaction: The emergence of 'workplace studies'. Br. J. Sociol. 2000, 51, 299-320. [CrossRef]

31. Borgatta, E.F.; Cottrell, L.S., Jr.; Mann, J.H. The spectrum of individual interaction characteristics: An inter-dimensional analysis. Psychol. Rep. 1958, 4, 279-319. [CrossRef]

32. Pejovich, $\mathrm{S}$. The effects of the interaction of formal and informal institutions on social stability and economic development. J. Mark. Moral. 1999, 2, 164.

33. Ko, C.; Haney, M.H.; Lee, G. Effects of ethical leadership and formal control systems on employee opportunistic behavior in China. Benchmarking Int. J. 2018. [CrossRef]

34. Pillemer, J.; Rothbard, N.P. Friends without benefits: Understanding the dark sides of workplace friendship. Acad. Manag. Rev. 2018, 43, 635-660. [CrossRef]

35. Maseli, N.A.; Bakar, H.A. Social Interactions in the Workplace: Homophily and Structure in a Formal Organization. In Proceedings of the SMMTC Postgraduate Symposium 2018, Kedah, Malaysia, 18-19 March 2018; p. 310.

36. Winslow, C.J.; Sabat, I.E.; Anderson, A.J.; Kaplan, S.A.; Miller, S.J. Development of a Measure of Informal Workplace Social Interactions. Front. Psychol. 2019, 10, 2043. [CrossRef]

37. McGrath, E.; Cooper-Thomas, H.D.; Garrosa, E.; Sanz-Vergel, A.I.; Cheung, G.W. Rested, friendly, and engaged: The role of daily positive collegial interactions at work. J. Organ. Behav. 2017, 38, 1213-1226. [CrossRef]

38. Zhao, Y.; Cotelle, Y.; Sakai, N.; Matile, S. Unorthodox interactions at work. J. Am. Chem. Soc. 2016, 138, 4270-4277. [CrossRef]

39. Zabrodska, K.; Ellwood, C.; Zaeemdar, S.; Mudrak, J. Workplace bullying as sensemaking: An analysis of target and actor perspectives on initial hostile interactions. Cult. Organ. 2016, 22, 136-157. [CrossRef]

40. Maltarich, M.A.; Kukenberger, M.; Reilly, G.; Mathieu, J. Conflict in teams: Modeling early and late conflict states and the interactive effects of conflict processes. Group Organ. Manag. 2018, 43, 6-37. [CrossRef] 
41. Lybarger, J.E.; Rancer, A.S.; Lin, Y. Superior-Subordinate Communication in the Workplace: Verbal Aggression, Nonverbal Immediacy, and Their Joint Effects on Perceived Superior Credibility. Commun. Res. Rep. 2017, 34, 124-133. [CrossRef]

42. Shier, M.L.; Graham, J.R.; Nicholas, D. Interpersonal interactions, workplace violence, and occupational health outcomes among social workers. J. Soc. Work 2018, 18, 525-547.

43. Sun, H.; Wu, S.; Li, Y.; Dai, G. Tourist-to-Tourist Interaction at Festivals: A Grounded Theory Approach. Sustainability 2019, 11, 4030. [CrossRef]

44. Terblanche, N.S. Revisiting the supermarket in-store customer shopping experience. J. Retail. Consum. Serv. 2018, 40, 48-59. [CrossRef]

45. Papathanassis, A. Guest-to-guest interaction on board cruise ships: Exploring social dynamics and the role of situational factors. Tour. Manag. 2012, 33, 1148-1158. [CrossRef]

46. Duncan, S.; Fiske, D.W. Face-to-Face Interaction: Research, Methods, and Theory; Routledge: Abingdon, UK, 2015.

47. Williams, E. Experimental comparisons of face-to-face and mediated communication: A review. Psychol. Bull. 1977, 84, 963. [CrossRef]

48. Wang, T.K.; Brower, R. Job satisfaction among federal employees: The role of employee interaction with work environment. Public Pers. Manag. 2019, 48, 3-26. [CrossRef]

49. Chuang, P.-J.; Chiu, S.-F. When moral personality and moral ideology meet ethical leadership: A three-way interaction model. Ethics Behav. 2018, 28, 45-69. [CrossRef]

50. Zanozovska, $\mathrm{O}$. The effects of the quality of employees' interactions with their managers on the quality of their work. Balt. J. Econ. Stud. 2017, 3, 33-42. [CrossRef]

51. Furlich, S.A. Understanding employee motivation through managerial communication using expectancyvalence theory. J. Integr. Soc. Sci. 2016, 6, 17-37.

52. Meinecke, A.L.; Lehmann-Willenbrock, N.; Kauffeld, S. What happens during annual appraisal interviews? How leader-follower interactions unfold and impact interview outcomes. J. Appl. Psychol. 2017, 102, 1054. [CrossRef]

53. Johnson, S.J.; Machowski, S.; Holdsworth, L.; Kern, M.; Zapf, D. Age, emotion regulation strategies, burnout, and engagement in the service sector: Advantages of older workers. Rev. Psicol. Trab. Las Organ. 2017, 33, 205-216. [CrossRef]

54. Fasbender, U.; Burmeister, A.; Wang, M. Motivated to be socially mindful: Explaining age differences in the effect of employees' contact quality with coworkers on their coworker support. Pers. Psychol. 2019. [CrossRef]

55. Lin, I.Y.; Kwantes, C.T. Potential job facilitation benefits of "water cooler" conversations: The importance of social interactions in the workplace. J. Psychol. 2015, 149, 239-262. [CrossRef]

56. Bettencourt, L.A.; Gwinner, K.P.; Meuter, M.L. A comparison of attitude, personality, and knowledge predictors of service-oriented organizational citizenship behaviors. J. Appl. Psychol. 2001, 86, 29. [CrossRef] [PubMed]

57. Mardanov, I.; Cherry, J. Linkages among workplace negative behavioral incidents. Evid.-Based HRM: Glob. Forum Empir. Scholarsh. 2018, 6, 221-240. [CrossRef]

58. Choi, B.; Kim, H.S. The Impact of Servicescape on Customer Experience Quality through Employee-to-customer Interaction Quality and Peer-to-peer Interaction Quality in Hedonic Service Settings. Asia Mark. J. 2015, 17, 73-96. [CrossRef]

59. Bakker, A.; Demerouti, E.; Schaufeli, W. Dual processes at work in a call centre: An application of the job demands-resources model. Eur. J. Work Organ. Psychol. 2003, 12, 393-417. [CrossRef]

60. Jiang, T.; Chen, X.; Sun, Q. The Exploration and Analysis of the Influence Factors for Staff Interactive Relationship. In International Conference on Applied Human Factors and Ergonomics; Springer: Berlin, Germany, 2017; pp. 547-556.

61. Lee, M.C.C.; Idris, M.A.; Delfabbro, P.H. The linkages between hierarchical culture and empowering leadership and their effects on employees' work engagement: Work meaningfulness as a mediator. Int. J. Stress Manag. 2017, 24, 392. [CrossRef]

62. Lotila, P. Corporate responsiveness to social pressure: An interaction-based model. J. Bus. Ethics 2010, 94, 395-409. [CrossRef]

63. Zhou, F.; Wu, Y.J. How humble leadership fosters employee innovation behavior. Lead. Organ. Dev. J. 2018, 39, 375-387. [CrossRef] 
64. Wall, A.E.; Smith, R.A.; Nodoushani, O. Bullying in the workplace: The great balancing act of victim rights and organizational policies. J. Compet. Stud. 2018, 26, 107-123.

65. Cortina, L.M.; Magley, V.J.; Williams, J.H.; Langhout, R.D. Incivility in the workplace: Incidence and impact. J. Occup. Health Psychol. 2001, 6, 64. [CrossRef] [PubMed]

66. Tews, M.J.; Michel, J.W.; Noe, R.A. Does fun promote learning? The relationship between fun in the workplace and informal learning. J. Vocat. Behav. 2017, 98, 46-55. [CrossRef]

67. Griffiths, D.; García-Peñalvo, F.J. Informal learning recognition and management. Comput. Hum. Behav. 2016, 55, 501-503. [CrossRef]

68. Suhartanto, D.; Dean, D.; Nansuri, R.; Triyuni, N.N. The link between tourism involvement and service performance: Evidence from frontline retail employees. J. Bus. Res. 2018, 83, 130-137. [CrossRef]

69. Elmadağ, A.B.; Ellinger, A.E. Alleviating job stress to improve service employee work affect: The influence of rewarding. Serv. Bus. 2018, 12, 121-141. [CrossRef]

70. Chancellor, J.; Layous, K.; Margolis, S.; Lyubomirsky, S. Clustering by well-being in workplace social networks: Homophily and social contagion. Emotion 2017, 17, 1166. [CrossRef]

71. Fornes, G.; Cardoza, G. Internationalization of Chinese SMEs: The perception of disadvantages of foreignness. Emerg. Mark. Financ. Trade 2019, 55, 2086-2105. [CrossRef]

72. Li, N.; Toppinen, A.; Lantta, M. Managerial perceptions of SMEs in the wood industry supply chain on corporate responsibility and competitive advantage: Evidence from China and Finland. J. Small Bus. Manag. 2016, 54, 162-186. [CrossRef]

73. Chew, Y.-T.; Yeung, H.W. The SME advantage: Adding local touch to foreign transnational corporations in Singapore. Reg. Stud. 2001, 35, 431-448. [CrossRef]

74. Thoti, K.K.; Saufi, R.B.A. Empirical Study on Work Life Integration Practices in Electronic Industry. Int. J. Res. Econ. Soc. Sci. IJRESS 2016, 6, 275-284.

75. Franceschini, I.; Siu, K.; Chan, A. The "rights awakening" of Chinese migrant workers: Beyond the generational perspective. Crit. Asian Stud. 2016, 48, 422-442. [CrossRef]

76. Liu, X.; Huang, G.; Huang, H.; Wang, S.; Xiao, Y.; Chen, W. Safety climate, safety behavior, and worker injuries in the Chinese manufacturing industry. Saf. Sci. 2015, 78, 173-178. [CrossRef]

77. Glaser, B.G.; Strauss, A.L. Discovery of Grounded Theory: Strategies for Qualitative Research; Routledge: Abingdon, UK, 2017.

78. Ting, H.; Thurasamy, R. What matters to infrequent customers: A pragmatic approach to understanding perceived value and intention to revisit trendy coffee café. SpringerPlus 2016, 5, 651. [CrossRef] [PubMed]

79. Ting, C.Y.; Ismail, M.B.; Ting, H.; Bahri, S.B.; Sidek, A.B.; Idris, S.F.B.; Tan, R.T.H.; Seman, S.S.B.A.; Sethiaram, M.R.A.; Ghazali, M.H.B.M. Consumer behaviour towards pharmaceutical products: A model development. Int. J. Pharm. Healthc. Mark. 2019. [CrossRef]

80. Thomson, S.B. Sample size and grounded theory. Thomson SB 2010 Grounded Theory-Sample Size. J. Adm. Gov. 2010, 5, 45-52.

81. Edhlund, B.; McDougall, A. Nvivo 12 Essentials; Lulu: Morrisville, NC, USA, 2019.

82. Aragón-Correa, J.A.; Martín-Tapia, I.; Hurtado-Torres, N.E. Proactive environmental strategies and employee inclusion: The positive effects of information sharing and promoting collaboration and the influence of uncertainty. Organ. Environ. 2013, 26, 139-161. [CrossRef]

83. Schachter, S. The interaction of cognitive and physiological determinants of emotional state. In Advances in Experimental Social Psychology; Elsevier: Amsterdam, The Netherlands, 1964; Volume 1, pp. 49-80.

84. Dror, O.E. Deconstructing the "two factors": The historical origins of the Schachter-Singer theory of emotions. Emot. Rev. 2017, 9, 7-16. [CrossRef]

85. Ashkanasy, N.M.; Humphrey, R.H.; Huy, Q.N. Integrating emotions and affect in theories of management. Acad. Manag. Rev. 2017, 42, 175-189. [CrossRef]

86. Hao, F. Ideological Expectations for Value Consensus in Chinese Society. Soc. Sci. China 2016, 37, 41-56. [CrossRef]

87. Zeng, R.; Chen, Y.; Li, H. Participation in collective action in china: Unfair experience, interests involved, and political efficacy. Soc. Behav. Pers. Int. J. 2018, 46, 1561-1572. [CrossRef]

88. Krishnan, T.N.; Scullion, H. Talent management and dynamic view of talent in small and medium enterprises. Hum. Resour. Manag. Rev. 2017, 27, 431-441. [CrossRef] 
89. Gilman, M.; Raby, S. National context as a predictor of high-performance work system effectiveness in small-to-medium-sized enterprises (SMEs): A UK-French comparative analysis. Int. J. Hum. Resour. Manag. 2013, 24, 372-390. [CrossRef] 